\title{
Phenotypic shift in human differentiated gastric cancers from gastric to intestinal epithelial cell type during disease progression
}

\author{
Akemi Yoshikawa ${ }^{1,2}$, Ken-ichi Inada $^{1}$, Takasuke Yamachika $^{1}$, Nobuyuki Shimizu ${ }^{1,2}$, Michio Kaminishi ${ }^{2}$, \\ and Masae Tatematsu ${ }^{1}$ \\ ${ }^{1}$ Laboratory of Pathology, Aichi Cancer Center Research Institute, 1-1 Kanokoden, Chikusa-ku, Nagoya 464-8681, Japan \\ ${ }^{2}$ Department of Gastrointestinal Surgery, Postgraduate School of Medicine, The University of Tokyo, Tokyo, Japan
}

\begin{abstract}
:
Background. The phenotypic expression of tumor cells is widely thought to resemble that of the tissue of origin. In the present study, to assess phenotypic changes that occur with disease progression, we investigated human differentiated gastric cancers at different depths of invasion for component cancer cell types.

Methods. Using a combined mucin histochemical and immunohistochemical approach, we classified surgical specimens of 301 differentiated gastric cancers into three types: gastric epithelial cell (G) type, intestinal epithelial cell (I) type and mixed gastric and intestinal (GI) type, according to the phenotypic differentiation of the component cancer cells. The relation between the phenotypic type of cancer and their depth of invasion was evaluated.

Results. The proportion of $\mathrm{G}$ type cancers was $41.4 \%$ in early (tumor invasion of mucosa or submucosa) cases, decreasing to $\mathbf{2 2 . 2} \%$ in advanced (tumor invasion of muscularis propia or deeper) cases, whereas the proportion of I type cancers increased with progressive disease from $23.5 \%$ to $31.1 \%(P<$ 0.01). Cancers invading the subserosa or deeper included more I type cases and fewer $G$ type than cancers limited to the mucosa $(P<0.01)$. In most cases of each phenotypic type, intestinal metaplasia was recognized in the surrounding background mucosa, but no clear relation was shown between the phenotype of cancers and the degree of intestinal metaplasia in the background mucosa, suggesting that intestinal metaplasia is not always a preneoplastic lesion.

Conclusions. A phenotypic shift from G to I type expression was observed with the progression of human differentiated gastric cancers. Intestinalization may occur independently in cancerous and noncancerous gastric mucosa.
\end{abstract}

Key words: human differentiated gastric cancer, differentiation phenotype, phenotypic change, intestinalization, preneoplastic lesion

Offprint requests to: A. Yoshikawa

Received for publication on May 1, 1998; accepted on Oct. 22, 1998

\section{Introduction}

The phenotypic expression of tumor cells is widely thought to resemble that of the tissue of origin. Accordingly, examination of the phenotypic expression of gastric cancers should reveal their histogenesis. Developments in mucin histochemistry and immunohistochemistry have made it possible to readily determine the differentiation phenotype of individual gastric noncancerous and cancerous cells. Using this approach, it is possible to classify human gastric cancer cells into four types of gastric or intestinal epithelial cell characteristics $[1,2]$.

Histologically, human gastric carcinomas have been classified into two main groups, namely, the "intestinal" and "diffuse" types of Lauren [3]. The former corresponds to the "differentiated" type and the latter to the "undifferentiated" type of Nakamura et al. [4] and Sugano et al. [5]. The frequency of intestinal metaplasia in the surrounding mucosa has been compared in the two types, and consequently intestinal metaplasia has been considered as a preneoplastic lesion for the differentiated ("intestinal" type) adenocarcinoma [3-5].

We have previously shown that experimentally induced adenocarcinomas in rat glandular stomach consisted mainly of gastric epithelial cell type cancer cells, and that the intestinal epithelial cell type cancer cells appeared later in the larger tumors, suggesting a phenotypic shift from gastric to intestinal type expression during the course of tumor progression [6-10]. We have also shown that this phenotypic shift occurred in accordance with increasing depth of invasion in human gastric signet ring cell carcinomas, which are widely recognized to originate from gastric mucosa proper [11].

In the present study, to clarify the histogenesis and phenotypic shift that occurs with the progression of human differentiated gastric carcinomas, we evaluated 301 surgical specimens for their component cells, using a 
combined mucin histochemical and immunohistochemical approach.

\section{Patients and methods}

\section{Samples}

We evaluated specimens from 301 patients with primary differentiated gastric cancer (tubular [tub] 1, tub 2, and papillary [pap], according to the Japanese Classification of Gastric Carcinoma [12]) resected surgically at Aichi Cancer Center Hospital between 1990 and 1993. Of the 301 cancer patients, 231 were men and 70 were women; they ranged in age from 38 to 84 years (mean, $62.7 \pm 9.3$ years).

All specimens were fixed in $10 \%$ buffered formalin. Carcinomas with adjacent nonneoplastic mucosa were cut serially into 5 -mm slices in parallel with the lesser curvature and embedded in paraffin. Tissue sections stained with hematoxylin and eosin were examined and those with the deepest invasive front were selected for mucin histochemical and immunohistochemical approach. The depth of invasion was judged according to the criteria of the Japanese Classification of Gastric Carcinoma [12].

\section{Mucin histochemistry and immunohistochemistry}

For mucin histochemistry, we employed galactose oxidase-Schiff (GOS) [13] and paradoxical concanavalin A staining (PCS) [14] techniques. For immunohis- tochemistry, we used SH-9 [15,16], anti-pepsinogen II (Pg II) [17], TKH-2 [18,19], $91.9 \mathrm{H}$ [20-22], and antisucrase [23] antibodies. The characteristics of each marker and the donors of the antibodies are listed in Table 1.

GOS-reactive mucins have been demonstrated in surface mucous cells of the fundic and pyloric mucosa. By PCS, mucins in the alimentary tract can be divided into two main classes: class III mucins in mucous neck cells, pyloric gland cells, and Brunner's gland cells and class II mucins in surface mucous cells, goblet cells, and the surface coat of intestinal absorptive cells. In this study, we used PCS identifying class III mucin. GOS and PCS staining procedures were performed as described previously $[13,14]$. The avidin-biotin-peroxidase complex (ABC) immunohistochemical method [24] (Vectastain Elite ABC kit, Burlingame CA, USA) was employed for immunohistochemistry. SH-9 reacts with nonneoplastic human tissues such as endocervical and bronchial epithelia and, in the alimentary tract, is specific for surface mucous cells of the fundic and pyloric mucosa. Immunohistochemical localization of Pg II has been demonstrated in mucous neck cells and chief cells of the fundic glands and mucous cells of the pyloric and Brunner's glands. TKH-2, in the alimentary tract, reacts with goblet cell mucin in normal small intestine and intestinal metaplasia. $91.9 \mathrm{H}$, which was raised against purified normal colonic sulfomucin, is frequently positive in goblet cells and columnar cells in intestinal metaplastic glands of the stomach and gastric cancer cells, although it is completely negative in normal gastric

Table 1. Mucin histochemical and immunohistochemical differentiation markers

Mucin histochemistry

Galactose oxidase-Schiff (GOS)

Positive for surface mucous cell type mucin.

Paradoxical concanavalin A staining (PCS) (type III mucin staining)

Positive for type III much (mucous neck cell, pyloric gland cell and Brunner's gland cell type mucin).

Immunohistochemistry

SH9 Monoclonal antibody raised against a 49-kD peptide fragment of the CA-125 bearing antigenic molecule secreted from a human ovarian serous cystadenocarcinoma cell strain.

Positive for surface mucous cells of the fundic and pyloric mucosa (kindly donated by Dr. Shunsuke Imai, Department of Pathology, Nara Medical University, Nara, Japan).

Pg II Polyclonal antibody raised against human pepsinogen II.

Positive for mucous neck and chief cells of the fundic glands, pyloric gland cells and Brunner's gland cells (kindly donated by Dr. Kazumasa Miki, Faculty of Medicine, the University of Tokyo, Tokyo, Japan).

TKH-2 Monoclonal antibody which recognizes mucin-associated sialyl Tn antigen.

Positive for goblet cell mucin in normal small intestine and intestinal metaplasia (kindly donated by Dr. J.L. Werther, Gastrointestinal Research Laboratory, Mount Sinai Medical Center, NY, USA).

91.9H Monoclonal antibody raised against purified sulfomucin from normal colonic mucosa.

Positive for normal colonic epithelial cells and frequently positive for goblet cells and columnar cells in intestinal metaplastic glands of the stomach and gastric cancer cells (kindly donated by Dr. Tatsuro Irimura, Faculty of Pharmaceutical Sciences, University of Tokyo, Tokyo, Japan).

Sucrase Polyclonal antibody raised against human sucrase.

Positive for striated cell border of mature intestinal absorptive cells (kindly donated by Dr. Kazuyuki Hirano, Department of Pharmaceutics, Gifu Pharmaceutical University, Gifu, Japan). 
mucosa. Anti-sucrase antibody reacts with the luminal surface of mature intestinal absorptive cells.

GOS, PCS class III mucin, SH-9, and Pg II are markers of the gastric epithelial cell $(\mathrm{G})$ phenotype, whereas TKH-2, 91.9H, and sucrase are markers of the intestinal epithelial cell (I) phenotype.

\section{Phenotypic expression of gastric cancer cells}

Using the staining mentioned above, we classified gastric cancer cells into four phenotypic types (Table 2).

Surface mucous cell $(\mathrm{Su})$ type. Cancer cells of this type contained GOS and/or SH-9 reactive mucins.

Pyloric gland cell (Py) type. Cancer cells of this type contained class III mucin and/or showed Pg II reactivity.

Intesinal absorptive cell $(A b)$ type. Cancer cells of this type formed tubular or papillary structures with incomplete striated cell borders and occasionally showed sucrase and/or $91.9 \mathrm{H}$ reactivity.

Goblet cell (Go) type. Cancer cells of this type contained TKH-2 and/or 91.9H-positive mucin.

The $\mathrm{Su}$ and Py types we classified as gastric epithelial cell $(G)$ type cancer cells and the Ab and Go types as intestinal (I) type cancer cells.

\section{Classification of cancers}

Gastric cancers in which more than $90 \%$ of the sectional area consisted of $G$ type cancer cells were classified as $G$ type cancers and those containing I type cancer cells in more than $90 \%$ of their sectional areas were classified as I type cancers. Intermediate cases (i.e., cancers consisted of $\mathrm{G}$ and I type cancer cells, neither of which reaching more than $90 \%$ dominance) were classified as gastric and intestinal mixed (GI) type cancers and specimens in which most component cancer cells showed no reactions for any of the staining procedures used in this study were treated as unclassified.

\section{Evaluation of intestinal metaplasia}

The specimens were divided into three grades according to the extent of intestinal metaplasia of surrounding background mucosa: (1) minimal (intestinal mataplastic glands occupying less than $10 \%$ of mucosae), (2) moderate (intestinal mataplastic glands occupying between $10 \%$ and $90 \%$ of mucosae), and (3) marked (intestinal metaplastic glands occupying more than $90 \%$ of mucosae). As the nomenclature for intestinal metaplasia, we used Inada's recent classification, which relates to the cellular differentiation of metaplastic glands [25]. In that classification, intestinal metaplastic glands are divided into two main categories according to the presence or absence of gastric epithelial cell phenotype expression: (i) gastric and intestinal mixed type (GI type) intestinal metaplasia, and (ii) solely intestinal type (I type) intestinal metaplasia. In his original classification, each type is further divided into subtypes according to the component cells.

\section{Statistical analysis}

Ridit analysis was applied to compare the proportions of each photo type of gastric cancer in cancers with different depths of invasion. $P<0.01$ was regarded as statistically significant.

\section{Results}

\section{Phenotypic expression of gastric cancer cells}

Many cases showed the coexistence of G and I type cancer cells. Some cancer cells had the characteristics of more than one type e.g., the simultaneous secretion of both SH-9-and TKH-2-positive mucin (Su type and Go type, respectively) was occasionally seen. However, the methods used in this study allowed the lesions to be

Table 2. Classification of gastric cancer cell phenotype based on mucin histochemical and immunohistochemical findings

\begin{tabular}{|c|c|c|c|c|c|c|c|c|c|}
\hline \multicolumn{8}{|c|}{ Differentiation criteria } & \multirow{2}{*}{\multicolumn{2}{|c|}{$\begin{array}{l}\text { Phenotypic } \\
\text { expression }\end{array}$}} \\
\hline PCS & Pg II & GOS & SH-9 & TKH-2 & $91.9 \mathrm{H}$ & Sucrase & $\begin{array}{l}\text { Striated } \\
\text { cell border }\end{array}$ & & \\
\hline Class III & $(+)$ & $(-)$ & $(-)$ & $(-)$ & $(-)$ & $(-)$ & $(-)$ & Py type & \\
\hline Class II & $(-)$ & $(+)$ & $(+)$ & $(-)$ & $(-)$ & $(-)$ & $(-)$ & Su type & \\
\hline Class II & $(-)$ & $(-)$ & $(-)$ & $(+)$ & $(+/-)$ & $(-)$ & $(-)$ & Go type & I \\
\hline Class II & $(-)$ & $(-)$ & $(-)$ & $(-)$ & $(+/-)$ & $(+/-)$ & $(+)$ & Ab type & \\
\hline
\end{tabular}

PCS, Paradoxical concanavalin A staining; Pg II, pepsinogen II; GOS, galactose oxidase-Sciff; Py type, pyloric gland cell type; Su type, surface mucous cell type; Go type, goblet cell type; Ab type, intestinal absorptive cell type; G type, gastric epithelial cell type; I type, intestinal epithelial cell type 
classified into G, GI, and I types according to the proportion of each type of component cells. Overall, of the 301 cases examined, 98 were G type, 89 were GI type, 81 were I type, and 33 cases were unclassified. In invasive cancers, there was no phenotypic difference between cancer cells in the mucosal area and those at the deep invasive front, irrespective of the histological expansive or infiltrative mode of infiltration.

\section{Organoid differentiation of intramucosal cancer cells}

Intramucosal cancer cases showing organoid differentiation $[26,27]$ of cancer cells were frequent. These mimicked pyloric gland mucosa (Su type cancer cells occupying the upper, and Py type cancer cells occupying the lower regions; Fig. 1), GI type intestinal metaplastic mucosa (Su type, Go type, and Ab type cancer cells occupying the upper and Py type cancer cells occupying the lower regions; Fig. 2), or I type intestinal metaplastic mucosa (Go type and Ab type cancer cells occupying the mucosa; Fig. 3).

\section{Phenotypic shift of gastric cancer cells with disease progression}

The frequency of each phenotype of cancer in relation to depth of invasion is shown in Fig. 4. In the mucosal cancers limited to mucosa $(\mathrm{m})$, including muscularis mucosae (mm), $40.4 \%$ were $G$ type and $22.1 \%$ were I type, whereas in cancers invading as deep as subserosa (ss) $18.9 \%$ were $G$ type and $43.2 \%$ were I type, and in cancers invading the serosa and the peritoneal cavity (serosa-exposed, se) and invading in adjacent structures (serosa-infiltrating, si), $17.2 \%$ were $\mathrm{G}$ type and $26.6 \%$ were I type. The ss, se, and si cancers had significantly fewer $\mathrm{G}$ type and more I type cancers than the mucosal cancers $(P<0.01)$. A comparison between early (tumor invasion of mucosa or submucosa) and advanced (tumor invasion of muscularis propia or deeper) cancers also showed a significant difference (G type, $41.0 \%$ vs $22.2 \%$; I type, $23.5 \%$ vs $31.1 \%$; $P<0.01$ ).

\section{Relation of cancer phenotype and surrounding mucosa}

In most cases of each phenotypic type, intestinal metaplasia was recognized in the surrounding background mucosa. Twenty-five of $98 \mathrm{G}$ type cancers were surrounded by marked intestinal metaplastic mucosa and 15 by minimal metaplastic mucosa. Fifteen of 81 I type cancers were surrounded by minimal intestinal metaplastia and 16 by marked intestinal metaplastia. There was no clear relation between the phenotypic expression of the gastric cancers and the surrounding mucosa. In evaluation limited to mucosal cancers the finding was similar (Table 3).

\section{Discussion}

In previous studies [1,2], we classified the differentiation of gastric cancer cells into four types according to staining with PCS, GOS, sialidase-GOS, and Pg I and II

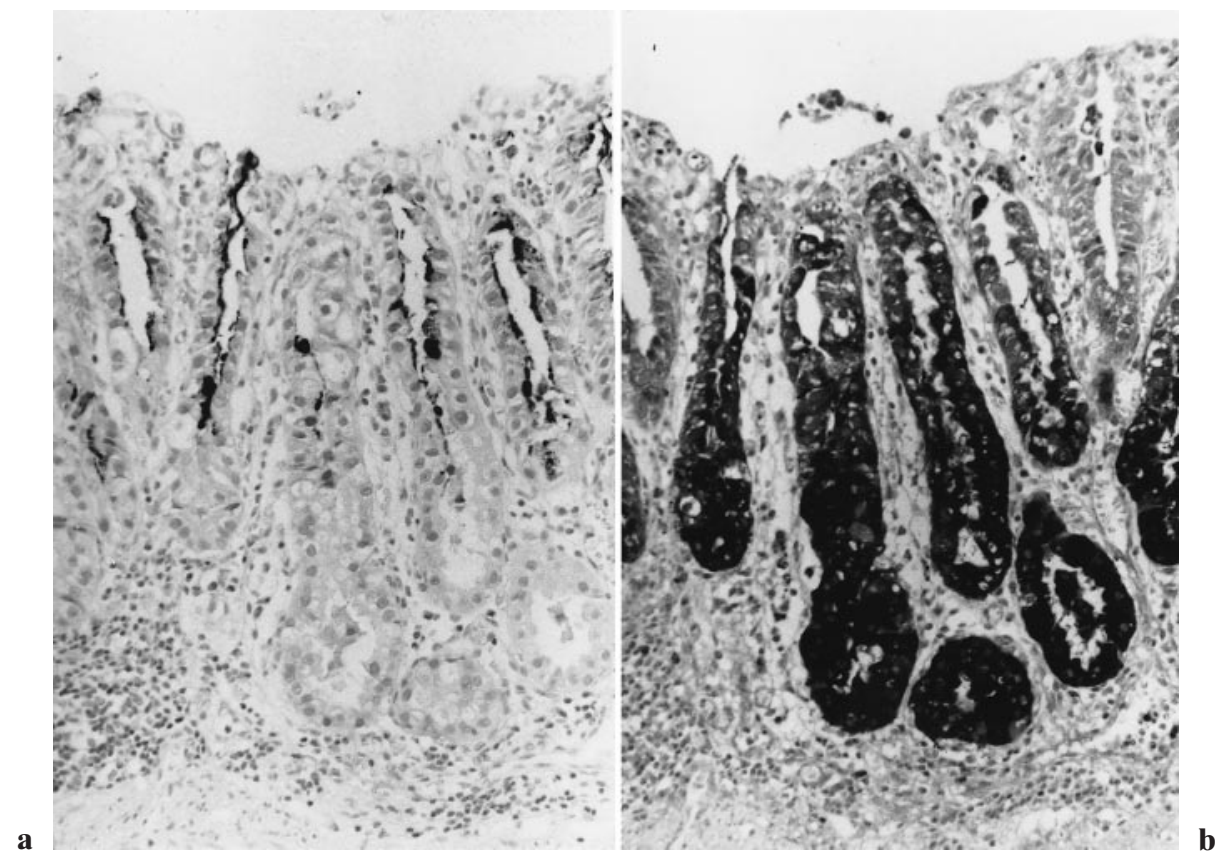

Fig. 1a,b. Gastric ( $G$ ) type mucosal gastric cancer. a Stained with $\mathrm{SH}-9$; b stained with anti-pepsinogen II (Pg-II). $\mathrm{SH}-9$-positive surface mucous cell $(\mathrm{Su})$ type cancer cells in the upper region and PgII-positive pyloric gland cell (Py) type cancer cells in the lower region, showing organoid differentiation mimicking pyloric gland mucosa (original magnification, $\times 250$ ) 
antibodies: Su and Py types (G type) and Ab and Go types (I type). In the present study, we added four new markers $(\mathrm{SH}-9, \mathrm{TKH}-2,91.9 \mathrm{H}$, and anti-sucrase antibodies) to determine the differentiation of class III mucin-negative cells more precisely. In the normal adult human alimentary tract, sialomucin is dominant in the small intestine and sulfomucin in the large intestine. However, this distribution is not universal in other spe- cies or in the developing human fetus [28-31], so in this study of cancer tissues, we did not regard TKH-2 or $91.9 \mathrm{H}$ as specific markers of the small or large intestinal phenotype, but used them as general markers of intestinal phenotype.

Lauren [3] classified gastric carcinomas as "intestinal" and "diffuse" types. Nakamura et al. [4] and Sugano et al. [5] classified gastric cancers as "differenti-
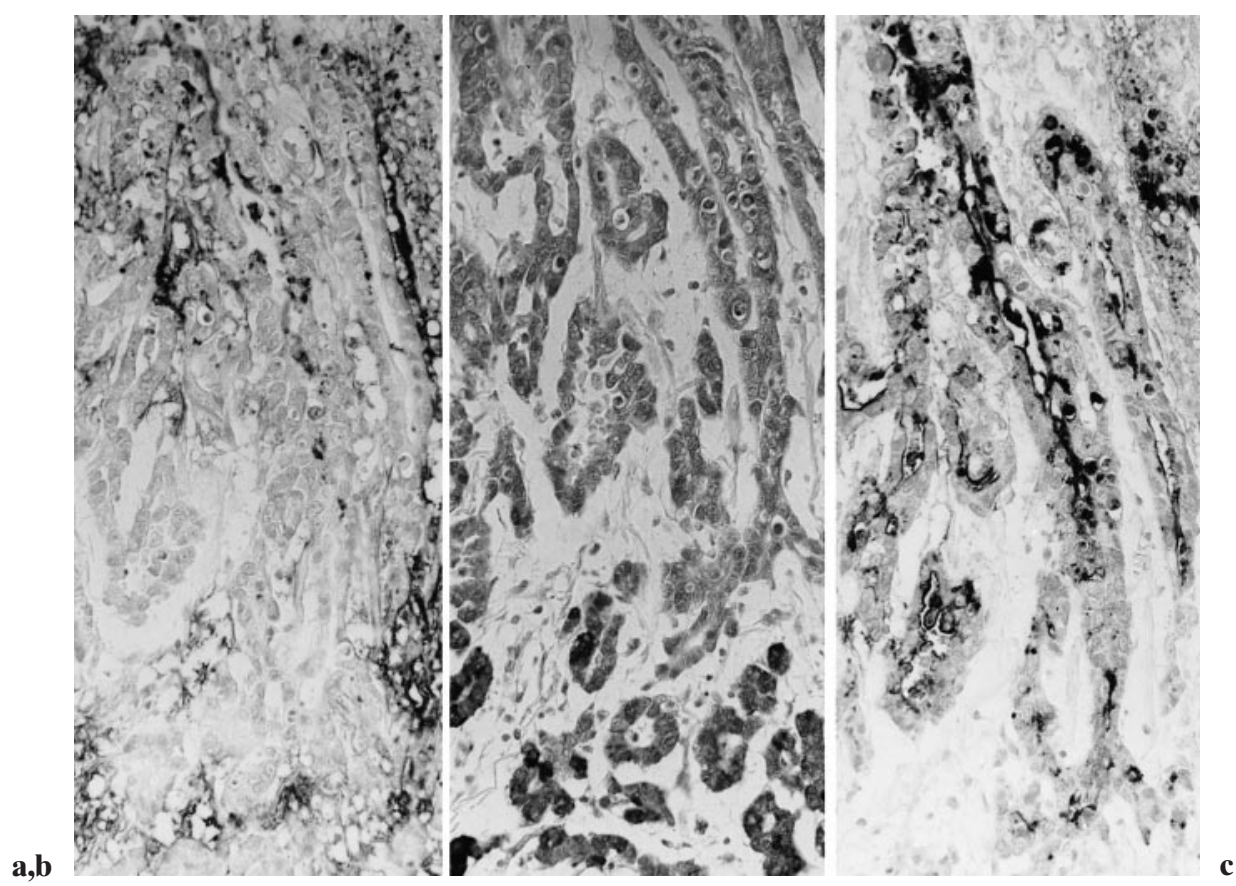

c

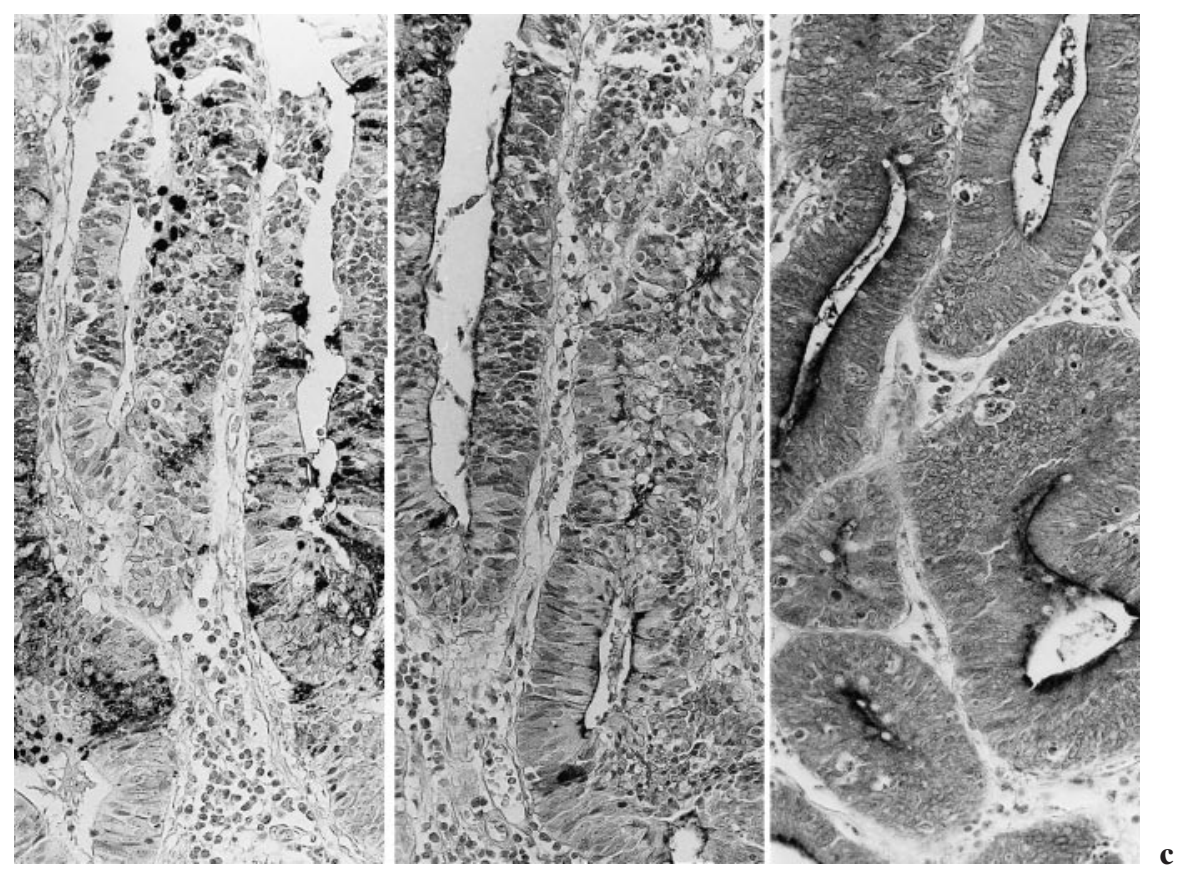

Fig. 2a-c. Mixed gastric and intestinal (GI) type mucosal gastric cancer. a Stained with SH-9; b stained with PgII; c stained with TKH-2. SH-9-positive Su type cancer cells and TKH-2 positive goblet cell (Go) type cancer cells were mixed in the upper region, and PgIIpositive Py type cancer cells were recognized in the lower region, showing organoid differentiation mimicking GI type intestinal metaplasia (original magnification, $\times 200$ )
Fig. 3a-c. Intestinal (I) type mucosal gastric cancer. a Stained with TKH-2; b stained with $91.9 \mathrm{H}$, c stained with sucrase. Note intestinal absorptive cell (Ab) type cancer cells with sucrase expression and $91.9 \mathrm{H}$-positive striated cell borders and scattered Go type cancer cells with TKH-2- and/or 91.9H-positive mucin showing I type differentiation (original magnification, $\times 300)$ 


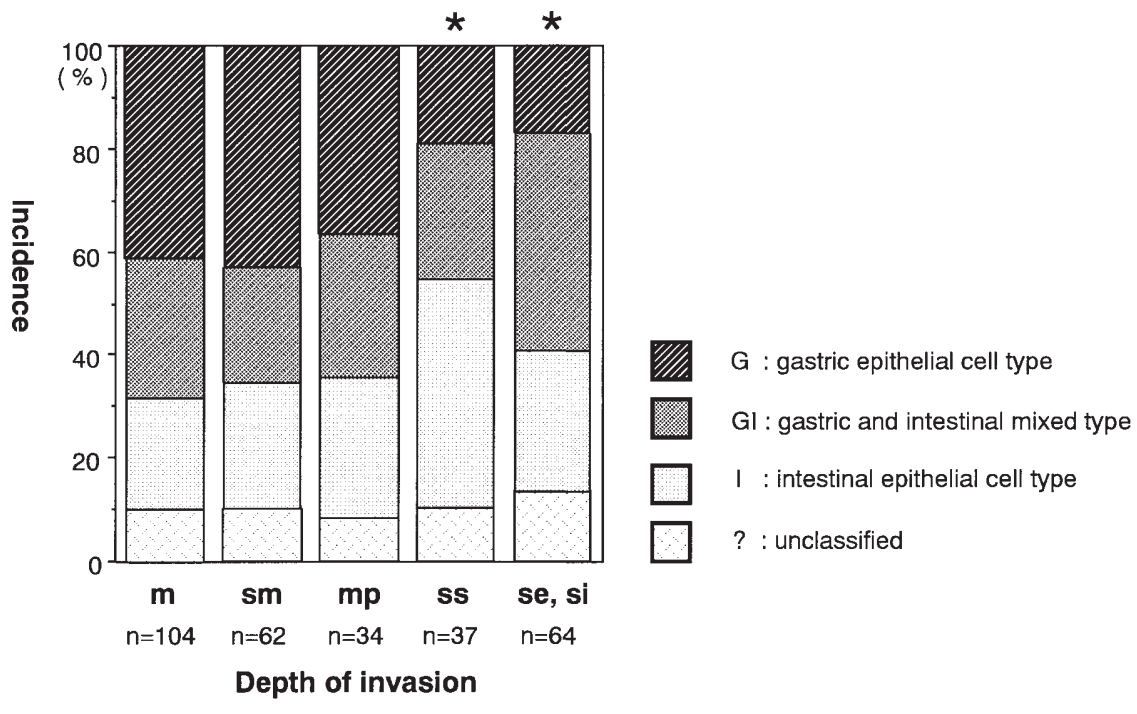

Fig. 4. Depth of invasion and differentiation phenotype in differentiated gastric cancers. ${ }^{*} P<0.01$ vs m. $m$, mucosa; $s m$, submucosa; $m p$, muscularis propria; ss, subserosa; se, si, serosa-exposed, serosainfiltrating

Table 3. Relation between phenotypic expression of differentiated gastric cancers and properties of surrounding mucosa

\begin{tabular}{|c|c|c|c|c|c|c|}
\hline IM & $\begin{array}{c}\text { Age } \\
\text { (years) }\end{array}$ & No. of cases & G & GI & I & $?$ \\
\hline \multicolumn{7}{|c|}{ Mucosal cancer cases } \\
\hline Minimal & $62.9 \pm 14.8$ & 11 & 5 & 5 & 1 & 0 \\
\hline Moderate & $60.7 \pm 9.6$ & 64 & 27 & 19 & 14 & 4 \\
\hline Marked & $61.0 \pm 8.7$ & 29 & 10 & 5 & 8 & 6 \\
\hline Total & $61.0 \pm 10.0$ & 104 & 42 & 29 & 23 & 10 \\
\hline \multicolumn{7}{|l|}{ All cases } \\
\hline Minimal & $61.8 \pm 11.1$ & 56 & 15 & 21 & 15 & 5 \\
\hline Moderate & $63.0 \pm 9.1$ & 185 & 58 & 58 & 50 & 19 \\
\hline Marked & $62.6 \pm 8.3$ & 60 & 25 & 10 & 16 & 9 \\
\hline Total & $62.7 \pm 9.3$ & 301 & 98 & 89 & 81 & 33 \\
\hline
\end{tabular}

Mucosal cancer, Invasion limited to mucosa, including muscularis mucosae

IM, Intestinal metaplasia; G, gastric epithelial cell type; GI, gastric and intestinal mixed type; I, intestinal epithelial cell type; ?, unclassified; minimal, $<10 \%$ intestinal metaplasia; moderate, $10 \%-90 \%$ intestinal metaplasia; marked, $>90 \%$ intestinal metaplasia

ated" and "undifferentiated" types (corresponding to Lauren's "intestinal" and "diffuse" types respectively). With regard to the histogenesis of gastric cancer, the frequency of intestinal metaplasia in the surrounding mucosa was commpared in the two types, and it was suggested that "intestinal" ("differentiated") type carcinomas arose in the intestinalized mucosa and "diffuse" ("undifferentiated") type carcinomas arose in the gastric mucosa proper [3-5]. However, contrary to this hypothesis, we found a high incidence of $G$ type differentiated mucosal cancers and a phenotypic shift from $\mathrm{G}$ to I type expression in accordance with increasing depth of invasion. Yamachika et al. [32] also found a phenotypic shift from $G$ to I type expression in their series of signet-ring cell carcinomas of the stomach, although they found no I type mucosal cancer cases. The tendency for a phenotypic shift was commonly recognized with increasing depth of invasion with both histological types.

With mucosal cancers, we often found organoid differentiation mimicking pyloric gland mucosa, GI type intestinal metaplastic mucosa, and I type intestinal metaplastic mucosa. This suggests that similar courses of intestinalization may have been in progress in nonneoplastic gastric mucosa and in the mucosal cancers. Another interpretation of this phenomenon is that cancers mimicking intestinal metaplasia originated from intestinal metaplastic glands. Some differentiated gastric cancers may have had an intestinal phenotype from very early in their development, and we do not rule out 
the possibility that the gastric cancers arose from already intestinalized glands showing intestinal metaplasia or gastric adenoma. GI type intestinal metaplasia with unstable cellular differentiation may give rise to early gastric cancers showing the GI phenotype. However, despite the presence of moderate to marked intestinal metaplasia in most of our cases $(89.4 \%$ in mucosal cancer cases and $81.4 \%$ in all cases), $40.4 \%$ of differentiated mucosal cancers were $\mathrm{G}$ type and only $22.1 \%$ were I type. No clear relation between the phenotypic expression of cancer cells and their surrounding mucosa was shown, so it is difficult to say that intestinal metaplasia is a preneoplastic lesion for differentiated gastric cancers. Hattori [33] investigated for microcarcinomas by a serial-step section method with conventional staining and suggested that a starting point for adenocarcinomas and dysplasias was in the prolifertive cell zone in the neck region. He concluded that intestinal metaplasia, dysplasia, and adenocarcinoma of the stomach arise coincidentally, with no precursor for any of them.

The apparent relation between the histological type of gastric cancer and intestinal metaplasia in the surrounding mucosa, together with the overall higher incidence of I type cancer cells in differentiated cancers, may reflect the phenotypic status of their background mucosa. Differentiated cancers do often develop in gastric mucosa with intestinal metaplasia. However, this does not mean that differentiated gastric cancers arise preferentially from intestinalized glands. This origin may be coincidental and it is possible that intestinal metaplasia and differentiated gastric cancers share a common background; in other words, intestinal metaplasia may be paraneoplastic, not preneoplastic. The background mucosa of differentiated gastric cancers may be prone to intestinalization. A common phenomenon observed among differentiated and undifferentiated gastric cancers and nonneoplastic gastric mucosa is the phenotypic shift to intestinalization, although the underlying mechanisms of this instability of cellular differentiation are yet to be elucidated.

In regard to the genetic background of intestinalization, changes in the expression of various genes determining cell structures and functions may be involved. Intestinalization differs from the nonsystematic deregulation of a single gene that is often seen during carcinogenesis; instead, it represents a kind of homeotic transformation [34,35]. Homeobox-containing genes (homeobox genes) play a key role in developmental processes. Recent evidence suggested the role of several homeobox genes in the malignant process [36-38]. Silberg et al. [36] showed that the homeobox gene $C D X 1$, which codes for an intestine-specific transcription factor that may be involved in the regulation of proliferation and differentiation of intestinal epithelial cells, was not expressed in normal stomach, but was expressed in intestinal metaplastic glands and sometimes in adenocarcinomas of the stomach. In the course of human ontogenesis, fetal stomach, which develops from the foregut, displays areas of "intestinal-type mucosa" with goblet cells and epithelial cells with striated borders in the antrum and cardia, as well as sulfomucin and sialomucin secretion $[31,39]$. Our findings for cancers may thus indicate a loss of ability to inhibit the primitive intestinal phenotype which was present in the fetal tissue but is normally inhibited in adult cells. A higher turnover rate of cells during development, regeneration, and carcinogesesis may lead to the appearance of cells that are less differentiated and possess the capacity to differentiate in both gastric and intestinal directions, perhaps with deregulation of homeobox gene expression.

We proposed earlier that the development of I type cells during experimentally induced rat gastric carcinogenesis occurred independently in nonneoplastic gastric mucosa and in gastric cancers [7]. We also showed that the intestinal phenotypic expression of cancer cells in rat stomach was stable and that the proportion of I type cancer cells was higher in larger tumors [8]. The findings of the present study are also consistent with the hypothesis that intestinalized cells may appear independently in normal gastric mucosa and in gastric cancers. Based on the idea of the monoclonal growth of tumors, it is assumed that individual cancers are derived from a single cell with intrinsic potential to differentiate into both $\mathrm{G}$ and I phenotypes, and the apparent phenotypic heterogeneity within cancers results from the phenotypic shift of cancer cells during progression. The observed phenotypic shift may be due to an intestinalization tendency in proliferating cancer cells or to differences in tumor biology (such as proliferative potential, apoptosis rates, and local aggressiveness) between $\mathrm{G}$ and I type cancer cells derived from the same original one cancer cell. The phenotypic shift from $\mathrm{G}$ to I type during the progression of gastric cancers may be of importance in the consideration of the biological behavior of gastric cancers in future studies.

\section{References}

1. Tatematsu $\mathrm{M}$, Ichinose $\mathrm{M}$, Miki $\mathrm{K}$, Hasegawa $\mathrm{R}$, Kato $\mathrm{T}$, Ito N. Gastric and intestinal phenotypic expression of human stomach cancers as revealed by pepsinogen immunohistochemistry and mucin histochemistry. Acta Pathol Jpn 1990;40:494504.

2. Tatematsu M, Hasegawa R, Ogawa K, Kato T, Ichinose M, Miki $\mathrm{K}$, et al. Histogenesis of human stomach cancers based on assessment of differentiation. J Clin Gastroenterol 1992;14(Suppl 1):S1-S7.

3. Lauren P. The two histological main types of gastric carcinoma: Diffuse and so-called intestinal-type carcinoma: An attempt at 
a histo-clinical classification. Acta Pathol Microbiol Scand 1965;64:31-49.

4. Nakamura K, Sugano H, Takagi K. Carcinoma of the stomach in incipient phase: Its histogenesis and histological appearances. Gann (Jpn J Cancer Res) 1968;59:251-8.

5. Sugano H, Nakamura K, Kato Y. Pathological studies of human gastric cancer. Acta Pathol Jpn 1982;32:329-47.

6. Tatematsu M, Katsuyama T, Fukushima S, Takahashi M, Shirai T, Ito $\mathrm{N}$, et al. Mucin histochemistry by paradoxical concanavalin A staining in experimental gastric cancers induced in Wistar rats by $\mathrm{N}$-methyl-N'-nitro-N-nitrosoguanidine or 4-nitroquinoline 1 oxide. J Natl Cancer Inst 1980;64:835-43.

7. Tatematsu M, Furihata C, Katsuyama T, Hasegawa R, Nakanowatari J, Saito D, et al. Independent induction of intestinal metaplasia and gastric gastric cancer in rats treated with N-methyl-N'-nitro-N-nitrosoguanidine. Cancer Res 1983;43: 1335-41.

8. Tatematsu M, Katsuyama T, Furihata C, Tsuda H, Ito N. Stable intestinal phenotypic expression of gastric and small intestinal tumor cells induced by N-methyl-N'-nitro-N-nitrosoguanidine or methylnitrosourea in rats. Gann (Jpn J Cancer Res) 1984;75:95765 .

9. Tatematsu M, Katsuyama T, Furihata C, Fukushima S, Shirai T, Kato T, et al. Cellular differentiation and histogenesis of rat glandular stomach cancers. Jpn J Cancer Res 1990;81:760-7.

10. Yuasa H, Hirano K, Kodama H, Nakanishi H, Imai T, Tsuda H, et al. Immunohistochemical demonstration of intestinal-type alkaline phosphatase in stomach tumors induced by N-methyl$\mathrm{N}^{\prime}$-nitro-N-nitrosoguanidine in rats. Jpn J Cancer Res 1994; 85:897-903.

11. Tatematsu M, Furihata C, Katsuyama T, Miki K, Honda H, Konishi Y, et al. Gastric and intestinal phenotypic expressions of human signet ring cell carcinomas revealed by the biochemistry, mucin histochemistry and ultrastructure. Cancer Res 1986;46: 4866-72.

12. Japanese Research Society for Gastric Cancer. Japanese classification of gastric carcinoma. 1st English edn. Tokyo: Kanehara; 1995.

13. Katsuyama T, Ono K, Nagata T. Application of galactose oxidase mucosubstance histochemistry: Galactose oxidase-Schiff reaction. J Histochem Cytochem 1982;30:555.

14. Katsuyama T, Spicer SS. Histochemical differentiation of complex carbohydrates with variants of the concanavalin A horseradish peroxidase method. J Histochem Cytochem 1978;26:23350 .

15. Imai S, Maeda H, Kiyozuka Y, Morimoto J, Haga S, Noda T, et al. Monoclonal antibodies against CA125-bearing antigenic molecule fragments; reactivity with mucinous ovarian tumours and lung cancers. Mol Cell Probes 1991;5:55-63.

16. Tatematsu M, Iwata H, Ichinose M, Kakei N, Tsukada S, Miki K, et al. Markers of surface mucous cell type human gastric cancer cells: Galactose oxidase-Schiff reactive mucins, monoclonal antibody $\mathrm{SH}-9$ reactive mucins and cathepsin E. Acta Pathol Jpn 1993;43:500-6.

17. Huang SC, Miki K, Sano J, Ichinose M, Kawamura N, Oka H, et al. Pepsinogens I and II in gastric cancer: An immunohistochemical study using monoclonal antibodies. Jpn J Cancer Res 1988;79:1139-46.

18. Kjeldsen $\mathrm{T}$, Clausen $\mathrm{H}$, Hirohashi S, Ogawa T, Iijima H, Hakomori S. Preparation and characterization of monoclonal antibodies directed to the tumor-associated O-linked sialosyl- $2 \rightarrow 6$ $\alpha-\mathrm{N}$-acetylgalactosaminyl (sialosyl-Tn) epitope. Cancer Res 1988:48:2214-20.

19. Iwata H, Itzkowitz SH, Werther JL, Hayashi K, Nakamura H, Ichinose $\mathrm{M}$, et al. Expression of sialosyl-Tn in intestinal type cancer cells of human gastric cancers. Acta Pathol Jpn 1993;43:646-53.
20. Yamori T, Ota DM, Cleary KR, Hoff S, Hager LG, Irimura T. Monoclonal antibody against human colonic sulfomucin: Immunochemical detection of its binding sites in colonic mucosa, colorectal primary carcinoma and metastases. Cancer Res 1989;49:887-94.

21. Irimura T, Wynn DM, Hager LG, Cleary KR, Ota DM. Human colonic sulfomucin identified by a specific monoclonal antibody. Cancer Res 1991;51:5728-35.

22. Ohe Y, Hinoda Y, Irimura T, Imai K, Yachi A. Expression of sulfated carbohydrate chains detected by monoclonal antibody $91.9 \mathrm{H}$ in human gastric cancer tissues. Jpn J Cancer Res 1994;85:400-8.

23. Kano T, Usami Y, Adachi T, Tatematsu M, Hirano K. Inhibition of purified human sucrase and isomaltase by ethanolamine derivatives. Biol Pharm Bull 1996;19:341-4.

24. Hsu SM, Raine L, Fanger H. Use of avidin-biotin-peroxidase complex $(\mathrm{ABC})$ in immunoperoxidase techniques: A comparison between $\mathrm{ABC}$ and unlabeled antibody (PAP) procedures. J Histochem Cytochem 1981;29:577-80.

25. Inada K, Nakanishi H, Fujimitsu Y, Shimizu N, Ichinose M, Miki $\mathrm{K}$, et al. Gastric and intestinal mixed and solely intestinal types of intestinal metaplasia in the human stomach. Pathol Int 1997;47:831-41.

26. Nakamura Y. Appearance of gastric phenotypes and organoid structure in gastric cancer of differentiated type (in Japanese with English abstract). Sinsyu Med J 1991;39:731-44.

27. Fujimori Y, Akamatsu T, Ota H, Katsuyama T. Proliferative markers in gastric carcinoma and organoid differentiation. Hum Pathol 1995;26:725-34.

28. Ballard WW. The digestive apparatus. In: Ballard WW, editor. Comparative anatomy and embryology. New York: Ronald Press Publisher; 1964:455-72.

29. Lev R, Orlic D. Histochemical and radioautographic studies of normal human fetal colon. Histochemistry 1974;39:301-11.

30. Itzkowitz SH, Yuan M, Montgomery CK, Kjeldsen T, Takahashi HK, Bigbee WL, et al. Expression of Tn sialosyl-Tn, and T antigens in human colon cancer. Cancer Res 1989;49:197204.

31. Stauffer A, Lallemand A, Gaillard D. Histochimie des mucines du tube digestif chez le foetus humain (in French with English abstract). Gastroenterol Clin Biol 1990;14:561-6.

32. Yamachika T, Inada K, Fujimitsu Y, Nakamura S, Yamamura Y, Kitou T, et al. Intestinalization of gastric signet ring cell carcinomas with progression. Virchows Archiv A 1997;431:103-10.

33. Hattori T. Development of adenocarcinomas in the stomach. Cancer 1986;57:1528-34.

34. Slack JM. Homoeotic transformations in man: Implications for the mechanism of embryonic development and for the organization of epithelia. J Theor Biol 1985;114:463-90.

35. Slack JM. Epithelial metaplasia and the second anatomy. Lancet 1986;II:268-71.

36. Silberg DG, Furth EE, Taylor JK, Schuck T, Chiou T, Traber PG. CDX1 protein expression in normal, metaplastic, and neoplastic human alimentary tract epithelium. Gastroenterology 1997;113: 478-86.

37. Vider BZ, Zimber A, Hirsch D, Estlein D, Chastre E, Prevot S, et al. Human colorectal carcinogenesis is associated with deregulation of homeobox gene expression. Biochem Biophys Res Commun 1997;232:742-8.

38. Mallo GV, Rechreche H, Frigerio JM, Rocha D, Zweibaum A, Lacasa M, et al. Molecular cloning, sequencing and expression of the mRNA encoding human Cdx1 and Cdx2 homeobox. Downregulation of $\mathrm{Cdx} 1$ and $\mathrm{Cd} \times 2$ mRNA expression during colorectal carcinogenesis. Int J Cancer 1997;74:35-44.

39. Salenius P. On the ontogenesis of the human gastric epithelial cells: A histologic and histochemical study. Acta Anat 1962; 50(Suppl 46):1-76. 